\title{
Evaluation of the Therapeutic Effect of Low Level Laser in Controlling Low Back Pain: A Randomized Controlled Trial
}

\author{
Leyla Kholoosy ${ }^{1}$, Dariush Elyaspour ${ }^{2}$, Mohammad Reza Akhgari ${ }^{3}$, Zahra Razzaghi ${ }^{1}$, Zeinab Khodamardi ${ }^{4}$, \\ Masume Bayat ${ }^{*}$ \\ ${ }^{1}$ Laser Application in Medical Sciences Research Center, Shahid Beheshti University of Medical Sciences, Tehran, Iran \\ ${ }^{2}$ Physical Medicine and Rehabilitation Research Center, Shahid Beheshti University of Medical Sciences, Tehran, Iran \\ ${ }^{3} \mathrm{MSc}$. Mechanical Engineering \\ ${ }^{4}$ Engineering Physics, Laser and Optics Orientation B.S \\ ${ }^{5}$ Physical Medicine and Rehabilitation specialist, Shahid Beheshti University of Medical Sciences, Tehran, Iran
}

\author{
*Correspondence to \\ Masume Bayat, \\ Physical Medicine and \\ Rehabilitation specialist, Shahid \\ Beheshti University of Medical \\ Sciences, Tehran, Iran. \\ Email: \\ bayat.masume@yahoo.com
}

Published online March 15, 2020

\begin{abstract}
Introduction: Low back pain (LBP) is a very common musculoskeletal disorder. The big burden of disease necessitates investigating a more effective modality of treatments with more persistence and also fewer side effects. Low power laser has been proved as a pain reducing modality, but there is a lack of studies comparing it with other treatments and also among the Iranian race and society. The purpose of this study was to evaluate the effect of low-level laser on patients with LBP. Methods: Our study was a single-blind, randomized controlled trial. Forty subjects, aged between 20 to 70 with LBP participated in the study. Their pain severity scale was 3-10 according to the visual analogue scale of pain (VAS). They were randomly assigned to two groups, a case group (true laser) and a control group (sham laser). Naproxen was prescribed with a free dose (250-1000 mg/ daily) to both groups. We evaluated patients' subjective pain, functional status (using the Roland Morris disability questionnaire), spinal range of motion (ROM) and spinal tenderness at the basic time, one month and 3 months after treatment. The true laser group received 12 sessions of laser $(160 \mathrm{~mW})$ and the control group took 12 sessions of sham laser (the same laser instrument in off status). An infrared laser GaAlAs, wavelength $808 \mathrm{~nm}$, power $160 \mathrm{mw}$ and spot size $1 \mathrm{~cm}^{2}$ and power density $0.16 \mathrm{~J} / \mathrm{cm}^{2}$ in continuous mode was used in treatment. We applied the laser to articular spaces of vertebral column, adjacent paravertebral points, pain radiating areas, tender points and also pain-controlling acupuncture points.

Results: Of the 40 participants in the study, 6 persons were excluded and thus the data obtained from 34 participants were statistically analyzed. There was significant improvement in pain $(P<0.001$ for both groups), functional status (Case group: $P<0.001$; control group: $P=0.004$ ) and spinal ROM (Case group: $P<0.001$; control group: $P=0.007$ ) in both groups at the end of the first month, but these gains persisted for 3 months only in the case group $(P<0.001)$. Regarding spinal tenderness, it was disappeared in $89.47 \%$ of the patients in the true laser group at the end of one month but remained unchanged in $73.33 \%$ of the subjects of the sham laser group.

Conclusion: We concluded that laser therapy (in combination with NSAIDs) is an effective and long-lasting therapeutic strategy in bringing relief from LBP without any significant side effect.

Keywords: Low back pain; Low-level laser therapy; GaAIAs laser.
\end{abstract}

\section{Introduction}

Low back pain (LBP) is a very common musculoskeletal disorder. It is estimated that about $80 \%$ of human beings experience at least one episode of LBP throughout their life. ${ }^{1}$ There are different underlying pathologies with the potency of causing LBP. Some of the commonest include strain, sprain, facet joint or intervertebral disk pathologies, spondylolysis/spondylolisthesis, scoliosis, degenerative spine disorders, and lumbar canal stenosis.
Mechanical LBP is defined as LBP without a distinctly identifiable pathology and is said to be the commonest cause of back pain.

There are different treatment methods proposed for controlling LBP. Some popular strategies include medical treatments, physiotherapy, exercise, surgery, acupuncture and massage. ${ }^{2}$ Currently, some new therapeutic strategies are also introduced. One of these methods is laser therapy. Low power laser is recently tried in

Please cite this article as follows: Kholoosy L, Elyaspour D, Akhgari MR, Razzaghi Z, Khodamardi Z, Bayat M. Evaluation of the therapeutic effect of low level laser in controlling low back pain: a randomized controlled trial. J Lasers Med Sci. 2020;11(2):120-125. doi:10.34172/ jlms.2020.21. 
different rheumatologic, neurologic and musculoskeletal disorders such as osteoarthritis, ${ }^{3-4}$ rheumatoid arthritis, ${ }^{5,6}$ fibromyalgia, ${ }^{7,8}$ carpal tunnel syndrome, ${ }^{9}$ rotator cuff tendinitis, ${ }^{10-12}$ and chronic back pain syndromes. ${ }^{13-15}$ It has resulted in considerable achievements in most of the studied conditions. It was approved by the Food and Drug Administration (FDA) as a safe analgesic modality in 2007. ${ }^{16}$ The mechanism of pain reduction attributed to the laser is through a chain of vasodilation, increased drainage of interstitial fluid, and finally breaking the spasm, edema and pain vicious cycle. ${ }^{17}$ An increased level of electromagnetic energy caused by laser leads to increased ATP metabolism and cellular membrane repolarization. ${ }^{18}$ It also blocks pain signal transfer to the central nervous system. ${ }^{19}$ The other positive effect is an increase in the pain threshold. Furthermore, a variety of biological mechanisms such as the neurophysiologic effects (decreased nerve conduction velocity) ${ }^{20}$ and the release of the endogenous opioids ${ }^{21}$ are identified as contributors to pain reduction associated with the laser.

Nowadays, nonsteroidal anti-inflammatory drugs (NSAIDs) are vastly used in order to control pain. Although they are proved to be effective pain killers, their known side effects cannot be overlooked. Given that some of their side effects such as gastrointestinal bleeding are potentially fatal, finding alternative treatments with fewer harmful effects is now the matter of interest.

Generally, there are few investigations assessing the effect of laser on LBP and the results are inconsistent. Considering the high incidence of LBP, the satisfactory results of laser in other conditions and the noninvasive and harmless nature of this method, we designed this study to evaluate the effect of low level laser therapy on chronic LBP.

\section{Patients and Methods}

This study was conducted by Laser Application in Medical Science Research Center of Shahid Beheshti University of Medical Sciences in Tehran. Also, this study is a randomized clinical trial, registered in the Iranian Registry of Clinical Trials (IRCT) (identifier: IRCT20111121008146N32). Inclusion criteria were as follows: complaint of chronic nonspecific nonradicular LBP (>3 months). Subjects with a history of motor or sensory deficits, pregnancy, NSAIDs-induced serious gastrointestinal problems such as bleeding/perforation, a need to emergent/urgent surgery, malignancy, active gastric ulcers, aspirin sensitivity, Rheumatologic diseases and undertreated severe depression were excluded from the study. Finally, 40 subjects participated in the study (Figure 1). Their age ranged from 20 to 70 and their pain severity was 3-10 according to the visual analogue scale

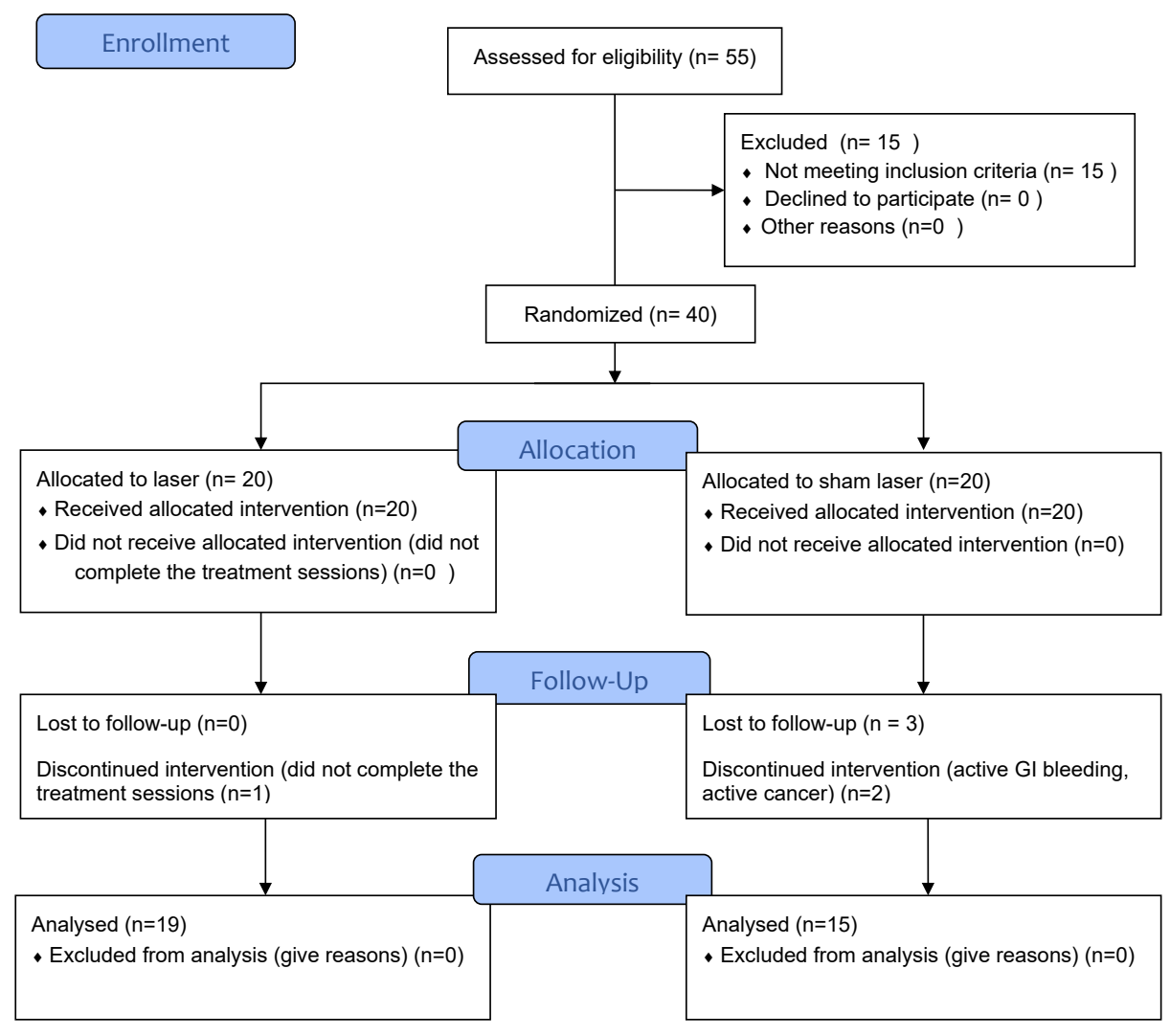

Figure 1. Flow Diagram of the Study. 
of pain (VAS). ${ }^{22}$ The patients were fully informed by the laser therapist physician and all signed a written informed consent form.

The study was designed as a single-blind, randomized controlled trial. The patients in the present study were randomly assigned to two groups, the case (true laser) and the control (sham laser). Each group consisted of 20 patients. The sampling was through simple randomization table. Subjects in both groups took the back protective instructions and were prescribed naproxen per need (up to $1000 \mathrm{mg}$ daily). Patients were informed not to use other pain reliever medications during the treatment course. They documented their daily naproxen use in a chart. Patients in the case group received 12 sessions of laser therapy with the frequency of 3 sessions per week. Laser characteristics were as follows: Infrared laser GaAlAs, wavelength $808 \mathrm{~nm}$, power $160 \mathrm{~mW}$ and penetration depth of $4 \mathrm{~cm}$. Control group attended 12 sessions of sham laser therapy, 3 times per week. The device was the same, but it was off during treatment sessions.

Patients' demographic characteristics, pain severity, functional status - using the validated Persian translation of the Roland Morris disability questionnaire (RMQ) $)^{23}$ - were obtained in a preliminary visit. They were also examined by a physician. The anterior and lateral flexion range of motion (ROM) of vertebral column (the finger to ground distance in $\mathrm{cm}$ in bending position) and also the existence of trigger points were assessed and the results were documented. Patients' previous images including radiography and/or MRI were also studied. For defining the pain severity, patients marked a point on a $10 \mathrm{~cm}$ scaled tape (VAS). Zero represented no pain and 10 showed very severe pain explained as delivery/renal stone pain.

We reevaluated the patients at the end of the first and third months after the treatment and all the abovementioned items were reassessed. Subjects who did not accomplish at least 5 sessions of therapy were excluded from the analysis. Also, the patients were asked for the appearance of the side effects due to low power laser or naproxen in each session and in post-treatment evaluations.

\section{Laser Therapy Protocol}

Technical specification: Infrared laser GaAlAs, wavelength $808 \mathrm{~nm}$, power $160 \mathrm{~mW}$, and spot size $1 \mathrm{~cm}^{2}$, power density 0.16 in continuous mode. It had been designed by Canadian Optic and Laser Center (COL Center) and sponsored partially by PTE company (Eshragh engineering group).

We applied the laser to articular spaces of vertebral column ( 3 points on each disc, 30 second each one, equals to $4.5 \mathrm{~J} / \mathrm{cm}^{2}$ each point), adjacent paravertebral points (1 point on each side, 30 seconds equals to $4.5 \mathrm{~J} / \mathrm{cm}^{2}$ each point), pain radiating areas and tender points (at least 12 points, with the dosage of $\left.4.5 \mathrm{~J} / \mathrm{cm}^{2}\right)$ and also paincontrolling acupuncture points (LI4, ST44, H7) with the dosage of $1.5 \mathrm{~J} / \mathrm{cm}^{2}$ (10 seconds each point). Points of focal Laser radiation were determined based on patient's examination findings.

\section{Data Analysis}

Statistical analysis was performed using SPSS 17 software. Qualitative variables were expressed in charts and tables. For quantitative variables (changes in pain severity, functional status, spinal ROM and tenderness) we used paired-samples $t$ test. In addition, analysis of variance was used for comparison of variables.

\section{Results}

Forty subjects including 12 males and 28 females took part in this study. Six patients were excluded from the analysis (3 did not accomplish the treatment and 3 were lost during follow up period, i.e, did not answer our calls). Therefore, the data obtained from 34 patients were analyzed. Demographic characteristics of subjects are shown in Table 1.

Changes in pain severity according to VAS are listed in Table 2. In the true laser group (case group), we found a significant pain reduction during the follow-up visits in the first $(P<0.001)$ and third $(P<0.001)$ months. In the sham laser group (control group) in the first-month visit, there was a significant decrease in pain $(P<0.001)$ but the changes were not significant in the third month $(P=1)$.

The results of the spinal ROM evaluation are listed in Table 3. At the end of the first month, both groups showed significant improvement in anterior and lateral flexion ROM (case group: $P<0.001$ and control group: $\mathrm{p}=0.007$ ). After 3 months, the gains of the case group in ROM persisted $(P<0.001)$. We could not follow the patients in the control group up to 3 months, so the data for the third-month follow-up visits are not available in the control group, but we asked them about the persistence of improvement and physical ability by the phone and their forms were completed.

Changes in spinal tenderness were as follow; in the pretreatment visit of the true laser group, $94.73 \%$ had some points of spinal tenderness in the physical examination. In the first-month follow-up visit, it was disappeared in $89.47 \%$ of patients. These changes persisted in the third-month follow-up visit. In the physical examination of the sham laser group, we found spinal tenderness in $86.65 \%$ of cases in the preliminary visit. This finding remained unchanged in $73.33 \%$ of subjects in the firstmonth follow-up. The third-month examination was not conducted in this group.

The patients' functional status score (according to RMQ) and its changes after treatment are shown in Table 4. We observed significant improvement in RMQ results observed in the case group at the end of the first $(P<0.001)$ and third months $(P<0.001)$. In the control group, there was also improvement in patients' RMQ score in the first-month visit $(P=0.004)$, but compared to the pre- 
Table 1. Patients' Demographics

\begin{tabular}{lccccc}
\hline & Total number & Female & Male & Mean age $(\mathbf{y})$ & Age range $(\mathbf{y})$ \\
\hline True laser & 20 & 13 & 7 & $47 \pm 10$ & $25-65$ \\
Sham laser & 20 & 15 & 5 & $51 \pm 11$ & $28-69$ \\
\hline
\end{tabular}

Table 2. Changes in Pain Severity (Mean VAS)

\begin{tabular}{lccc}
\hline & Before Treatment & 1 Month Follow up & 3 Months Follow up \\
\hline True laser & $6.2 \pm 1.1$ & $1.3 \pm 1.4$ & $1.1 \pm 1.4$ \\
Sham laser & $5.5 \pm 0.8$ & $4.3 \pm 1.2$ & $5.5 \pm 1.3$ \\
\hline
\end{tabular}

Table 3. Spinal ROM as the Distance From the Ground $(\mathrm{cm})$

\begin{tabular}{lcccc}
\hline \multirow{2}{*}{ True laser } & $\begin{array}{c}\text { Parameter } \\
\text { Evaluated }\end{array}$ & $\begin{array}{c}\text { Before } \\
\text { Treatment }\end{array}$ & $\begin{array}{c}\text { 1 Month } \\
\text { Follow up }\end{array}$ & $\begin{array}{c}\text { 3 Months } \\
\text { Follow up }\end{array}$ \\
\hline \multirow{3}{*}{ Sham laser } & Anterior flexion & $28 \pm 15$ & $13 \pm 12$ & $11 \pm 11$ \\
& Lateral flexion & $37 \pm 12$ & $20 \pm 12$ & $18 \pm 12$ \\
& Anterior flexion & $31 \pm 8$ & $21 \pm 8$ & Not evaluated \\
& Lateral flexion & $37 \pm 8$ & $34 \pm 9$ & Not evaluated \\
\hline
\end{tabular}

Table 4. Patients' Functional Status (According to RMQ)

\begin{tabular}{lccc}
\hline & Before Treatment & 1 Month Follow up & 3 Months Follow up \\
\hline True laser & $11.5 \pm 3$ & $6.8 \pm 3.6$ & $6.1 \pm 3.8$ \\
Sham laser & $11.3 \pm 4.2$ & $9.6 \pm 4.2$ & $11.8 \pm 4.1$ \\
\hline
\end{tabular}

treatment visit, no significant change was observed in the third-month follow-up $(P=0.1)$.

The results of the evaluation of the patients' satisfaction with the treatment process are listed in Table 5.

In the laser group, no side effect was reported following the use of naproxen, but in the sham laser group, some side effects were observed in 7 patients (40\%). Five patients were affected by mild non-bleeding gastrointestinal complications such as dyspepsia. It led to upper GI endoscopy in one case with the ultimate diagnosis of a duodenal ulcer. There was also one case of hematuria in a patient who had used an extra dosage of naproxen.

We evaluated the mean time of $50 \%$ pain reduction in the true laser group, which was about 5 sessions of treatment.

About 52\% of the patients in the true laser group reported a temporary increase in pain following the first treatment session.

\section{Discussion}

In reviewing articles we found some trials evaluating the effect of laser on LBP. The results were contradictory. In some studies, it was shown to be effective. ${ }^{24-26}$ Moreover, low energy laser acupuncture has been shown to be effective in subjects with nonspecific LBP. ${ }^{27}$ In a study by Hsieh, ${ }^{28}$ treatment with hot-pack therapy and 890-nm laser was associated with reductions in the severity of disability and fear-avoidance beliefs in patients with chronic LBP in an immediate post-treatment evaluation. On the other hand, there were studies finding no difference between real and sham laser. ${ }^{29}$ It is probable that increasing the emitted dose can improve the effectiveness of the laser. ${ }^{14}$ In our study, there was significant pain reduction in both groups at the end of the first month, but these effects persisted for 3 months only in the case group.

In the sham laser (control) group, no decrease in pain was observed at the third-month follow-up visit. Pain reduction at the end of the first month in this group was mainly due to naproxen use; therefore, it disappeared after discontinuing naproxen. The real effects of laser persisted for 3 months. The same results were obtained in functional status, spinal ROM and spinal tenderness in the evaluation of the case group patients at the end of one month and 3 months after treatment.

In sum, we observed significant pain reduction and improvement in spinal ROM and functional parameters in both groups at the end of the first month, but these gains persisted for 3 months only in the laser group. Subjects in the sham laser group showed no improvement after 3 months.

One major limitation of the current study was the concomitant use of naproxen. Although the rate of medication use was lower in the true laser group, the gains could be the result of the pain medications. A possible solution to this problem could be entering a third group who receive just naproxen and comparing the results of this group to the others. Another limitation was inaccessibility to the subjects in the sham laser group at 3-month follow-ups.

Surely further studies with a larger number of cases are needed to evaluate the probable side effects of the laser. It is also possible to compare pre- and post- treatment MRI, seeking for possible changes following treatment.

\section{Conclusion}

We concluded that the used low level laser (infrared laser GaAlAs, wavelength $808 \mathrm{~nm}$, power $160 \mathrm{~mW}$ and spot size $1 \mathrm{~cm}^{2}$, power density 0.16 , in Continuous mode) accompanied by naproxen is an effective and safe therapeutic method and has a more persistent disability

Table 5. Patient Satisfaction With Treatment

\begin{tabular}{|c|c|c|c|c|c|}
\hline & Time of Evaluation & Increase of Pain & No Change & Some Improvement & Significant Improvement \\
\hline \multirow{2}{*}{ True laser } & First month & 1 & 0 & 3 & 15 \\
\hline & Third month & 1 & 0 & 2 & 16 \\
\hline \multirow{2}{*}{ Sham laser } & First month & 8 & 5 & 2 & 0 \\
\hline & Third month & 14 & 1 & 0 & 0 \\
\hline
\end{tabular}


reducing and relieving effect on LPB patients in the group of true laser. In addition, the patients who were treated with the true laser needed a less amount of the rescue medication, and hence they experienced fewer side effects from the drug. We recommend this treatment to LBP patients who are not a candidate for surgical treatment.

\section{Ethical Considerations}

The ethics committee of Shahid Beheshti University of Medical Sciences approved the study by the code of 109 at 2011-12-10. The study protocol was designed with respect to the Declaration of Helsinki.

\section{Conflict of Interests}

The authors declare no conflict of interest.

\section{Acknowledgments}

We would like to express our thanks to Soheila Mokmeli, $\mathrm{MD}, \mathrm{PhD}$, anesthesiologist (educational administrator and laser therapy instructor; Canadian Optic and Laser (COL) Center, Victoria, British Colombia, Canada) and PTE (Eshragh engineering group) company for their great help in designing laser device, partially sponsorship and excellent scientific support.

\section{References}

1. Charlusz M, Gasztych J, Irzmanski R, Kujawa J. Comparative analysis of analgesic efficacy of selected physiotherapy methods in low back pain patients. Photomed Laser Surg. 2010;28(4):553-60

2. Kumar S, Beaton K, Hughes T. The effectiveness of massage therapy for the treatment of nonspecific low back pain: a systematic review of systematic reviews. Int J Gen Med. 2013;6:733-741

3. Soleimanpour H, Gahramani K, Taheri R, Golzari SE, Safari S, Esfanjani RM, Iranpour A. The effect of low-level laser therapy on knee osteoarthritis: prospective, descriptive study. Lasers Med Sci. 2014;29(5):1695-700. doi: 10.1007/ s10103-014-1576-6.

4. Kheshie AR, Alayat MS, Ali MM. High-intensity versus low-level laser therapy in the treatment of patients with knee osteoarthritis: a randomized controlled trial. Lasers Med Sci. 2014;29(4):1371-6. doi: 10.1007/s10103-0141529-0.

5. Brosseau L, Welch V, Wells G, Tugwell P, de Bie R, Gam A, et al. Low level laser therapy for osteoarthritis and rheumatoid arthritis: a metaanalysis. I Rheumatol. 2000;27(8):1961-1969.

6. Brosseau L, Robinson V, Wells G, Debie R, Gam A, Harman K. Low level laser therapy (Classes I, II and III) for treating rheumatoid arthritis. Cochrane Database Syst Rev. 2005 Oct 19;(4):CD002049.

7. Panton L, Simonavice E, Williams K, Mojock C, Kim JS, Kingsley JD, et al. Effects of Class IV laser therapy on fibromyalgia impact and function in women with fibromyalgia. J Altern Complement Med. 2013;19(5):445452.

8. Ruaro JA, Fréz AR, Ruaro MB, Nicolau RA. Low-level laser therapy to treat fibromyalgia. Lasers Med Sci. 2014;29(6):1815-1819. doi: 10.1007/s10103-014-1566-8.

9. Fusakul Y, Aranyavalai T, Saensri P, Thiengwittayaporn S. Low-level laser therapy with a wrist splint to treat carpal tunnel syndrome: a double-blinded randomized controlled trial. Lasers Med Sci. 2014;29(3):1279-87. doi: 10.1007/ s10103-014-1527-2.

10. Thornton AL, McCarty CW, Burgess MJ. Effectiveness of low-level laser therapy combined with an exercise program to reduce pain and increase function in adults with shoulder pain: a critically appraised topic. J Sport Rehabil. 2013;22(1):72-78.

11. Eslamian F, Shakouri SK, Ghojazadeh M, Nobari OE, Eftekharsadat B. Effects of low-level laser therapy in combination with physiotherapy in the management of rotator cuff tendinitis. Lasers Med Sci. 2012;27(5):951-958

12. Yavuz F, Duman I, Taskaynatan MA, Tan AK. Low-level laser therapy versus ultrasound therapy in the treatment of subacromial impingement syndrome: a randomized clinical trial. J Back Musculoskelet Rehabil. 2014;27(3):315320. doi: 10.3233/BMR-130450.

13. Zdrodowska B, Leszczyńska-Filus $\mathrm{M}$, Leszczyński R, Błaszczyk J. The influence of laser therapy on selected functional parameters of patients with spondyloarthrosis of the lower section of the spine. Pol Merkur Lekarski. 2014;36(212):101-105.

14. Jovicić M, Konstantinović L, Lazović M, Jovicić V. Clinical and functional evaluation of patients with acute low back pain and radiculopathy treated with different energy doses of low level laser therapy. Vojnosanit Pregl. 2012;69(8):656662.

15. Lin ML, Wu HC, Hsieh YH, Su CT, Shih YS, Lin CW, et al. Evaluation of the effect of laser acupuncture and cupping with ryodoraku and visual analog scale on low back pain. Evid Based Complement Alternat Med. 2012;2012:521612.

16. Mokammeli S. Comparing effect of LLLT with celecoxib in knee osteoarthritis. 8th WALT Congress; Norway; 2012

17. Hamblin MR, Demidova TN. Mechanisms of Low Level Light Therapy. SPIE website. https://www.spiedigitallibrary. org/conference-proceedings-of-spie/6140/614001/ Mechanisms-of-low-level-light-therapy/10.1117/12.646294. short?SSO=1. Published 10 February 2006.

18. Karu T. Laser biostimulation: a photobiological phenomenon. J Photochem Photobiol B. 1989;3(4):638-40.

19. Charłusz M, Gasztych J, Irzmański R, Kujawa J. Comparative analysis of analgesic efficacy of selected physiotherapy methods in low back painpatients. Ortop Traumatol Rehabil. 2010;12(3):225-36.

20. Walsh DM, Baxter GD, Allen JM. Lack of effect of pulsed low-intensity infrared $(820 \mathrm{~nm})$ laser irradiation on nerve conduction in the human superficial radial nerve. Lasers Surg Med. 2000;26(5):485-90.

21. Cambier D, Blom $\mathrm{K}$, witvrouw $\mathrm{E}$. The influence of low intensity infrared laser irradiation on conduction characteristics of peripheral nerve: a randomised, controlled, double blind study on the sural nerve. Lasers Med Sci. 2000;15(3):195-200. doi: 10.1007/PL00011317

22. Portenoy RK, Tanner RM. Pain Management: Theory and Practice. Oxford University Press, Inc; 1996.

23. Mousavi SJ, Parnianpour M, Mehdian H, Montazeri A, 
Mobini B. The Oswestry Disability Index, the RolandMorris Disability Questionnaire, and the Quebec Back Pain Disability Scale: translation and validation studies of the Iranian versions. Spine (Phila Pa 1976). 2006;31(14):E454459.

24. Konstantinovic LM, Kanjuh ZM, Milovanovic AN, Cutovic MR, Djurovic AG, Savic VG, et al. Acute low back pain with radiculopathy: a double-blind, randomized, placebocontrolled study. Photomed Laser Surg. 2010;28(4):553560 .

25. Djavid GE, Mehrdad R, Ghasemi M, Hasan-Zadeh H, Sotoodeh-Manesh A, Pouryaghoub G. In chronic low back pain, low level laser therapy combined with exercise is more beneficial than exercise alone in the long term: a randomized trial. Aust J Physiother. 2007;53(3):155-160
26. Bingöl U, Altan L, Yurtkuran M. Low-power laser treatment for shoulder pain. Photomed Laser Surg. 2005;23(5):459464.

27. Glazov G, Yelland M, Emery J. Low-dose laser acupuncture for non-specific chronic low back pain: a doubleblind randomised controlled trial. Acupunct Med. 2014;32(2):116-223.

28. Hsieh RL, Lee WC. Short-term therapeutic effects of 890-nanometer light therapy for chronic low back pain: a double-blind randomized placebo-controlled study. Lasers Med Sci. 2014;29(2):671-679. doi: 10.1007/s10103-0131378-2.

29. Ay S, Doğan SK, Evcik D. Is low-level laser therapy effective in acute or chronic low back pain? Clin Rheumatol. 2010;29(8):905-10. doi: 10.1007/s10067-010-1460-0. 